\title{
Sense of coherence and impact of oral health on quality of life in adults and elderly in Southern Brazil
}

\author{
Senso de coerência e impacto da saúde bucal na qualidade de vida \\ em adultos e idosos do sul do Brasil
}

Rosane Silvia Davoglio (https://orcid.org/0000-0003-1890-0982) ${ }^{1}$

Victor Nascimento Fontanive (https://orcid.org/0000-0002-6584-2167) ${ }^{2}$

Monica Maria Celestina de Oliveira (https://orcid.org/0000-0002-5197-9103) ${ }^{3}$

Claides Abegg (https://orcid.org/0000-0002-3808-2959) ${ }^{4}$

${ }^{1}$ Departamento de Ciências da Saúde, Universidade Federal de Santa Catarina. R. Gov. Jorge Lacerda 3201. Araranguá SC Brasil. rosanedavoglio@gmail.com ${ }^{2}$ Conceição Hospital Group. Porto Alegre RS Brasil.

${ }^{3}$ Saúde Coletiva,

Universidade Federal de Ciências da Saúde de Porto Alegre. Porto Alegre RS Brasil.

${ }^{4}$ Programa de Pós-

Graduação em Saúde

Coletiva, Universidade

Federal do Rio Grande do

Sul. Porto Alegre RS Brasil.

\begin{abstract}
This cross-sectional study aimed to investigate the association between the Sense of $\mathrm{Co}$ herence and impact of oral health on the quality of life. Was conducted with a sample of 720 individuals of both sexes, between the ages of 50 and 74 years, selected through multistage proportional random sampling. The data collection instruments used were: short version of the Sense of Coherence Scale (SOC-13), Oral Impacts on Daily Performances (OIDP) questionnaire, oral clinical examination and questionnaire containing socio demographic and use of dental services information. Bivariate and multivariate analyses were performed through Poisson regression adjusted for robust variance, with level of significance $p<0.05$. Oral impacts were reported by 416 participants (57.8\%). In the adjusted model, those with strong SOC were more likely of not having any impact when compared with individuals with weak SOC $(P R=1.30)$. Need for dental prosthesis was also associated with the outcome, individuals who did not require prosthesis had less impact $(P R=1.50)$. The findings showed that SOC is associated with OIDP, supporting the hypothesis that individuals with strong SOC present a lower impact of oral health on the quality of life, suggesting that $S O C$ is a determinant that can provide protection against that impact.
\end{abstract}

Key words Sense of Coherence, Oral Health, Quality of Life, Health Promotion
Resumo Este estudo transversal objetivou investigar a associação entre Senso de Coerência (SOC) e o impacto da saúde bucal na qualidade de vida. Foi realizado com uma amostra de 720 indivíduos de ambos os sexos, com idade entre 50 e 74 anos, selecionados por amostragem aleatória proporcional em múltiplos estágios. Os instrumentos de coleta de dados foram: versão curta da Sense of Coherence Scale, questionário Oral Impact on Daily Performance (OIDP), exame clínico bucal e questionário sociodemográfico e de uso de serviços odontológicos. As análises bivariadas e multivariadas foram realizadas por regressão de Poisson ajustada para variância robusta, com nivel de significância $p<0,05$. O impacto da saúde bucal foi relatado por 416 participantes (57,8\%). No modelo ajustado, aqueles com SOC forte foram mais propensos a não ter nenhum impacto, comparados aos indivíduos com SOC fraco $(P R=1,30)$. A necessidade de prótese dentária também foi associada ao desfecho e os indivíduos que não necessitavam prótese tiveram menor impacto $(P R=1,50)$. Os resultados mostraram que o SOC está associado ao OIDP, apoiando a hipótese de que os indivíduos com SOC forte apresentam menor impacto da saúde bucal na qualidade de vida, sugerindo que o SOC é um determinante que pode proporcionar proteção contra esse impacto.

Palavras-chave Sentido de Coerência, Saúde bucal, Qualidade de vida, Promoção de saúde 


\section{Introduction}

Sense of Coherence (SOC) is a psychosocial factor that can help individuals be better prepared to maintain and improve their health condition ${ }^{1}$, influencing self-perception and their quality of life ${ }^{2}$. SOC consists of an inner life guidance and ability to express the extent to which the individual has a deep and enduring, though dynamic, feeling of confidence in the following: that the stimuli derived from one's internal and external environments throughout life are structured, predictable and explicable (comprehensibility), that there are resources available to meet the demands resulting from these stimuli (manageability) and that these demands represent challenges that deserve commitment and investment (meaningfulness) ${ }^{3-5}$.

Studies from different countries show an association between strong SOC and reduced mortality risk, positive health self-perception and fewer subjective complaints and disease symptoms ${ }^{2,6-9}$. SOC was identified as a determinant of oral health-related behaviors in adolescents ${ }^{10}$ and adults ${ }^{11,12}$ and associated with self-reported gingivitis in adolescents ${ }^{13}$, regular dental visits in adults $^{11}$, better oral health-related quality of life ${ }^{14}$ and fewer problems attributed to clinical condition $^{14,15}$. Weak SOC has been shown to be associated with a frequency of tooth brushing of less than once a day, low level of oral hygiene ${ }^{16}$ and clinical temporomandibular dysfunction (TMD), with a higher prevalence of pain ${ }^{17}$.

Salutogenesis has been identified as an important resource that can be used in the field of health promotion ${ }^{1,2,9}$, and the literature has demonstrated that SOC may change throughout life $^{18}$. Therefore, finding ways to stimulate SOC in older age groups becomes an important strategy for raising the quality of life in adults and the elderly, as it may provide them with a greater ability and autonomy to manage their lives and make conscious choices, an essential factor for staying healthy.

Sense of Coherence is associated with overall quality of life $\mathrm{e}^{2,9}$ and oral health. Oral health related quality of life (OHRQoL) is integrated to general quality of life. Therefore, it may be argued that Sense of Coherence is associated with OHRQoL. The hypthesis is that individuals with high SOC are more likely of not presenting impact on their oral health quality of life.

The aim of this study is to investigate the relationship between SOC and OIDP, in adults and the elderly between the ages of 50 and 74 years in Porto Alegre-RS/Brazil.

\section{Method}

A population-based, cross-sectional study was conducted in adults living in Porto Alegre, Southern Brazil, from May 2008 to March 2009. This study is part of the research entitled "Assessment of Dental Impact on Daily Performance of Individuals between the ages of 50 and 74 years in Porto Alegre/RS."

\section{Sample}

The sample size was calculated considering a prevalence of Oral Impacts on Daily Performances of $50 \%$, a confidence interval of $95 \%$ and bilateral error margin of $4 \%$. Taking into account a design effect equal to 1.5 , and possible non-answers and losses (10\%), the final sample consisted of 793 subjects. To investigate the association between SOC and Oral Impacts on Daily Performance, the sample detects prevalence ratios equal or higher than 1,3 for an exposure equal or higher than $30 \%$, with a power of $80 \%$.

A multi-stage, proportional, random sampling was used. Out of the 16 health districts of the city, three were randomly selected ${ }^{19}$. Individuals included were aged 50-74 years and resided in the health district investigated. Only one individual from each household was interviewed. If there was more than one eligible individual, a randomized selection was done. Uninhabited homes, nursing homes, commercial establishments, non-resident visitors at the household, as well as individuals with apparent presence of cognitive impairment were excluded.

\section{Instruments and measures}

The data collection instruments used were the short version of Sense of Coherence scale (SOC-13) and the Oral Impact on Daily Performance (OIDP) questionnaire, which have been used before in Brazilian population ${ }^{10,20,21}$. The following were also used: a clinical examination form to assess oral health status and a questionnaire on sociodemographic data and the use of dental services, adapted from the Brazilian Oral Health Survey ${ }^{22}$. A pilot study was conducted in a convenience sample of 40 subjects with characteristics similar to those eligible for the study, to test the questionnaire application and to train the examiners. 


\section{SOC Scale}

The SOC- 13 consists of 13 items with answers presented on a 7-point Likert scale. The SOC score is the sum of all the items, ranging from 13 to 91 . The higher the score was, the stronger the SOC. In this study, the median was used as a cutoff point to dichotomized the SOC in "weak", for values lower than the median, and "strong" for values equal or greater than the median, similar to that adopted in other studies ${ }^{23,24}$.

When calculating the SOC score, four of the 13 questions were negatively formulated and scored inversely, e.g., their scores were inverted during analysis such that a high score represents a strong SOC. Subjects with missing values for more than 3 items would be treated as a loss and for subjects who had 3 or fewer missing values, these values would be replaced by the mean value of the other SOC items, as described by Suominen et al. $^{25}$. However, none of these situations happened in this study.

During the research, the reliability/reproducibility of the structured interviews and the clinical examinations were assessed with replication in $5 \%$ of the sample that was reassessed one week after the first evaluation. The intra- and inter-examiner agreement, evaluated by the Kappa index, was 0.98 and 0.88 , respectively. SOC reliability was tested by internal consistency and stability of measure (test-retest). The internal consistency of the overall score, calculated using the Cronbach's Alpha, was 0.80. A test-retest intraclass correlation coefficient (ICC) of 0.79 was found.

\section{OIDP questionnaire}

The OIDP questionnaire was developed by Adulyanon and Sheiham ${ }^{26}$ and originally contained 8 items. The version used in this study was adapted by Tsakos et al. ${ }^{27}$ and contained 10 items, and an additional item of working also included because it was considered to be of interest for this population. A cross-cultural adaptation of the instrument was conducted, including face-toface validation of contents and criteria by means of 3 pilot studies (with 35, 50 and 50 subjects) and a main study with 200 individuals ${ }^{28}$. The internalconsistency of the OIDP was 0.69 (Cronbach's Alpha). In the test-retest, the stability was also 0.69 , as measured by ICC.

The OIDP scoring system provides an individual score that quantifies the impacts and reflects their frequency and severity, allowing evaluation of the weight and relative importance that they have in everyday life, considering the perceptions of the respondent ${ }^{29}$. In addition to measuring the impact of oral health on the quality of life, the instrument also investigates the causes of it to assess specific treatment needs ${ }^{26}$. The time period adopted by the OIDP was the last 6 months, a period considered appropriate for common occurrences of oral conditions and also used in studies of chronic pain ${ }^{26}$. In the present study, the OIDP (no impact; impact) was the outcome.

\section{Sociodemographic variables}

Among the sociodemographic variables, age was collected in years and later categorized (5059 years; $60-74$ years) based on the World Health Organization guidelines, which consider the elderly to be individuals 60 years of age and older for developing countries. The age group 50-59 was included in the study because of its increase in the Brazilian population ${ }^{30}$. The income, collected as a continuous variable, took into account the gross family income in Brazilian Reais, categorized based on the prevailing Brazilian minimum wage of 415.00 Reais ( $\leq 2$ minimum wages; between 2 and 5 minimum wages; $>5$ minimum wages). Educational level was considered as the number of completed years of formal education, not counting repeated years, also including post graduate courses, and was dichotomized by the frequency distribution ( $<6$ years; $\geq 6$ years $)^{19}$.

\section{Variables related to oral health}

The investigated oral health-related variables included dental attendance within the previous year (yes; no) and the reason for attendance (curative; preventive) as reported by the participant, the need for dental prosthetics (yes; no), dental caries (yes; no) and number of teeth present (013 teeth; 14 or more teeth) obtained from the decayed, missing, filled teeth (DMFT) index during oral examination. The number of teeth present were categorized by the median, because the standard deviation was high and there was a concentration of the distribution at the extremes ${ }^{19}$. For the variable need for prosthesis (yes; no), was considered absence of need when the participant did not have dental loss or when dental loss had been rehabilitated with prosthesis and this was in adequate conditions.

Data were collected through interview using structured questionnaire and a clinical oral examination performed under artificial light, us- 
ing flat mirrors and CPI probes. First, the use and need of prostheses were recorded, followed by the evaluation of the condition of each tooth and the treatment need. Examiner training and calibration were conducted, according to the criteria defined by WHO, complemented by the Brazilian Epidemiological Survey/Brazil $2003^{22}$. The kappa coefficients for the assessment of the intra and inter-examiner reproducibility of all oral indices were 0.81 and 0.76 , respectively. The gold standard examiner was the one with the largest sum of intra-examiner Kappa values. The reproducibility of clinical oral health variables was assessed by reexamining of $5 \%$ of the study subjects one week after the first visit.

\section{Statistical Analysis}

Bivariate and multivariate analyses were performed through Poisson regression adjusted for robust variance using Stata 9.0 software (STATA, College Station, TX, USA). The analysis took into account the cluster sample and the sampling stages of this study. To ensure representativeness the sample was adjusted using the svyset-weight function in Stata 9.0 by sampling assigning different weights to each studied group ${ }^{19}$.

The level of statistical significance in all analyses was 5\% ( $\mathrm{p}<0.05)$. Initially, univariate analysis between the explanatory variables and the outcome was done. A significance level of $\leq$ 0.25 was established as the cutoff point for the selection of variables that would enter into the multivariate model to avoid the exclusion of potential confounding variable. Sociodemographic variables were included, regardless of the cutoff point.

Multivariate Poisson regression models were fit using the backward method. To define the final model, analyses were performed to identify possible confounding variables, and at each stage, variables that did not have at least 1 category with $\mathrm{p}<0.05$ were removed, starting with the highest $\mathrm{p}$ value. Thus, variables with $\mathrm{p}>0.05$ that $\mathrm{did}$ not cause changes in the risk estimates of others were excluded from the final model, with the exception of sociodemographic variables, which remained regardless of the observed results.

The study protocol was approved by the Research Ethics Committee of the Faculty of Dentistry, Federal University of Rio Grande do Sul.

\section{Results}

\section{Descriptive data}

The proportion of respondents was $91 \%$, and the mean participant age was 60.2 years $(\mathrm{SD}=$ 7.5). The SOC ranged from 23 to 91 , with a mean of 68 (SD $=12.2)$ and median of 69 . With respect to the sociodemographic distribution, high SOC scores were more frequent among women $(63.4 \%)$, those aged 60 years or older $(60.2 \%)$, those with over 6 years of schooling $(50.4 \%)$ and those with a family income between 2 and 5 minimum wages $(40.8 \%)$. The occurrence of dental impact on daily performance was reported by 416 participants $(57.8 \%)$.

\section{Sense of Coherence and Oral Health Impact on Quality of Life}

The results of the crude analyses between SOC and OIDP are shown in Table 1 and of the adjusted analyses in Table 2. The SOC was statistically associated with oral impact in the crude analyses, maintaining the association after adjustment for other variables in the model: those with a strong SOC were $30 \%$ more likely of not having oral impact $(\mathrm{PR}=1.30 ; 95 \% \mathrm{CI}=1.08$ 1.54) compared with those with a low SOC score. The need for dental prosthetesis was also associated with the outcome, of the crude and adjusted analyses, and individuals who did not require prosthetics had less impact $(\mathrm{PR}=1.50 ; 95 \% \mathrm{CI}$ $=1.29-1.80)$ than those who required it. The removal of this variable from the model caused little variation in the prevalence ratio between SOC and the outcome and thus did not influence this relationship.

\section{Discussion}

The findings of this study indicated that SOC is associated with OIDP. The association between SOC and the outcome was maintained after adjustments, demonstrating that this relationship remains even in the presence of other factors commonly associated with the impact on oral health related quality of life, revealing the importance of these results.

Individuals with a strong SOC reported significantly less oral impact than those with a weak SOC, suggesting that SOC may act as a factor that influences the self-perception of oral health ${ }^{15}$. This result is consistent with the idea that SOC is 
Table 1. Results of regression Poisson crude between the outcome no Oral Impacts on Daily Performances and Sense of Coherence $(n=720)$.

\begin{tabular}{|c|c|c|c|c|c|c|}
\hline \multirow{2}{*}{ Variables } & \multirow{2}{*}{$\mathbf{N}$} & \multirow{2}{*}{$\%$} & \multicolumn{4}{|c|}{ No Oral Impacts On Daily Performances } \\
\hline & & & $\mathbf{n}$ & $\%$ & PRcrude(IC 95\%) & p-value \\
\hline \multicolumn{7}{|l|}{ Sense of Coherence } \\
\hline Weak & 335 & 46.5 & 119 & 35.5 & 1.00 & - \\
\hline Strong & 385 & 53.5 & 184 & 47.8 & $1.33(1.12-1.60)$ & 0.001 \\
\hline \multicolumn{7}{|l|}{ Sex } \\
\hline Female & 416 & 57.8 & 206 & 42.7 & 1.00 & - \\
\hline Male & 304 & 42,2 & 97 & 40.8 & $0.95(0.79-1.15)$ & 0.579 \\
\hline \multicolumn{7}{|l|}{ Age } \\
\hline $60-74$ years & 338 & 46.9 & 178 & 43.2 & 1.00 & - \\
\hline $50-59$ years & 382 & 53.1 & 125 & 40.6 & $0.94(0.78-1.12)$ & 0.444 \\
\hline \multicolumn{7}{|l|}{ Income (family) } \\
\hline$\leq 2$ minimum wages & 191 & 26.5 & 72 & 37.7 & 1.00 & - \\
\hline Between 2 and 5 minimum wages & 287 & 39.9 & 119 & 41.5 & $1.08(0.87-1.36)$ & 0.482 \\
\hline 5 minimum wages & 242 & 33.6 & 112 & 46.3 & $1.21(0.97-1.52)$ & 0.097 \\
\hline \multicolumn{7}{|l|}{ Educational level } \\
\hline$<6$ years & 292 & 40.6 & 123 & 42.1 & 1.00 & - \\
\hline$>6$ years & 428 & 59.4 & 180 & 42.1 & $0.91(0.83-1.18)$ & 0.913 \\
\hline \multicolumn{7}{|c|}{ Dental Attendance within the previous year } \\
\hline No & 393 & 54.8 & 162 & 41.2 & 1.00 & - \\
\hline Yes & 324 & 45.2 & 140 & 42.2 & $1.04(0.87-1.23)$ & 0.640 \\
\hline \multicolumn{7}{|l|}{ Reason for Dental Attendance } \\
\hline Curative & 489 & 68.2 & 198 & 40.5 & 1.00 & - \\
\hline Preventive & 228 & 31.8 & 104 & 45.6 & $0.12(0.94-1.34)$ & 0.208 \\
\hline \multicolumn{7}{|l|}{ Dental caries } \\
\hline Yes & 240 & 33.3 & 107 & 55.6 & 1.00 & - \\
\hline No & 480 & 66.7 & 196 & 40.8 & $0.90(0.76-1.08)$ & 0.281 \\
\hline \multicolumn{7}{|l|}{ Number of teeth present } \\
\hline $0-13$ teeth & 371 & 51.5 & 157 & 42.3 & 1.00 & \\
\hline 14 or + teeth & 349 & 48.5 & 146 & 41.8 & $0.99(0.84-1.18)$ & 0.357 \\
\hline \multicolumn{7}{|l|}{ Need for dental prosthetics } \\
\hline Yes & 515 & 71.5 & 107 & 44.6 & 1.00 & - \\
\hline No & 205 & 28.5 & 196 & 40.8 & $1.58(1.33-1.85)$ & 0.000 \\
\hline
\end{tabular}

an inner guidance for life, which enables individuals to act positively on their health, facilitating the movement toward the positive pole on the health/disease continuum.

To our knowledge, this study is the first to investigate the relationship between SOC and OIDP, and therefore, there are no studies in the literature that can be used as a benchmark. However, research conducted on the Oral Health Impact Profile (OHIP), showed that for all quintiles of the SOC score, psychological distress was a major impact of oral condition on the quality of life ${ }^{14}$.
Previous studies have shown that the SOC is related to the overall quality of life $\mathrm{e}^{2,9}$ and oral health. Individuals with a strong SOC adopt more self-care measures, have better oral health habits and behaviors and visit the dentist more often and for preventive reasons ${ }^{11,14,15,31-33}$. In addition, these individuals have less tooth loss, fewer cavities and better oral health perception ${ }^{15}$, which can contribute both to a better clinical condition and to a positive health self-perception which is reflected in the impact reduction.

Oral clinical variables altered only slightly the prevalence ratio of the model, indicating 
Table 2 - Results of regression Poisson adjusted between the outcome and no Oral Impacts on Daily Performances and Sense of Coherence $(n=720)$.

\begin{tabular}{|c|c|c|}
\hline \multirow{2}{*}{ Variables } & \multicolumn{2}{|c|}{$\begin{array}{l}\text { No Oral Impacts On } \\
\text { Daily Performances }\end{array}$} \\
\hline & $\begin{array}{l}\text { PR adjusted } \\
\text { (IC 95\%) }\end{array}$ & p-value \\
\hline \multicolumn{3}{|l|}{ Sense of Coherence } \\
\hline Weak & 1.00 & - \\
\hline Strong & $1.30(1.08-1.54)$ & 0.004 \\
\hline \multicolumn{3}{|l|}{ Sex } \\
\hline Female & 1.00 & - \\
\hline Male & $0.95(0.79-1.14)$ & 0.571 \\
\hline \multicolumn{3}{|l|}{ Age } \\
\hline $60-74$ years & 1.00 & - \\
\hline $50-59$ years & $0.97(0.82-1.16)$ & 0.747 \\
\hline \multicolumn{3}{|l|}{ Income (family) } \\
\hline$\leq 2$ minimum wages & 1.00 & - \\
\hline $\begin{array}{l}\text { Between } 2 \text { and } 5 \\
\text { Minimum wages }\end{array}$ & $1.07(0.86-1.35)$ & 0.509 \\
\hline 5 minimum wages & $1.21(0.96-1.54)$ & 0.092 \\
\hline \multicolumn{3}{|l|}{ Educational level } \\
\hline$<6$ years & 1.00 & - \\
\hline$\geq 6$ years & $0.95(0.79-1.14)$ & 0.578 \\
\hline \multicolumn{3}{|l|}{$\begin{array}{l}\text { Need for dental } \\
\text { prosthetics }\end{array}$} \\
\hline Yes & 1.00 & \\
\hline No & $1.53(1.29-1.80)$ & 0.000 \\
\hline
\end{tabular}

that those who have a high SOC, even with unfavorable conditions such as cavities, tooth loss and the need for prosthetics, perceive less impact than those with a weak SOC. Currently, there is already evidence that the SOC is a health promotion resource that strengthens resilience and develops a positive health perception ${ }^{2,34}$.

Considering that the number of teeth present was not related to the impact on the quality of life, a reasonable assumption is that the position of teeth in the archc, e.g., having anterior teeth may be more important for SOC enhancement than having a greater number of teeth or having functional teeth (occluding posterior). A number of studies have shown that the elderly have a better acceptance of dental treatment when they believe it will benefit their self-esteem and social interaction than when they think it will bring functional improvement ${ }^{35-38}$. Thus, a strong SOC may also contribute to the enhancement of these resources.
In addition, the fact that no association was observed between number of teeth and the outcome may be concerned with the age of the sample and the reduction of expectations in relation to oral health that can occur throughout life. Older people tend to see tooth loss as a result of age accepting and adapting to $i^{38,39}$, specially in relation to posterior teeth.

In a population where the use of dental prosthesis is high, the impact caused by tooth loss can be reduced or compensated by prosthetic rehabilitation. The results of this study showed an association between need of prosthesis and oral impact, subjects who did not need dental prosthesis perceived less oral impact on daily performance. Tooth loss is often preceded by pain and discomfort, removal and replacement of teeth by prostheses (including full dentures) may be viewed by individuals as being a solution and not a problem. However, it is worth noting that these results may differ from other studies as they are related to specific cultural aspects of each population $^{40}$.

The present study did not find an association between sociodemographic factors and the oral impact on the quality of life. The occurrence of impact in the study sample was similar to results found by authors who investigated a population with a similar age group and high teeth $\operatorname{loss}^{29}$.

Cross-sectional studies are limited as the directionality of the events cannot be determined. However, it can be argued that it is plausible to assume that psychological factors, measured by the SOC, positively influence the perceived impact of oral health on quality of life. In addition, multivariate analyses, which controlled for potential confounding factors, added methodological value to the study.

This study is one of the first studies which investigates these associations in adults and the elderly. Given the changing demographic pattern and the oral health status specificities of this group, the present study stands out for its relevance in bringing information that may contribute to a greater quality of life for this population.

Another point that deserves attention is that in this research real outcomes are investigated which measure subjective perceptions of quality of life. Real outcomes are, by nature, clinically relevant outcomes that are understandable and tangible to the individuals, representing the subject's perception of the problem and not that of the professional ${ }^{41}$.

The satisfaction of the individuals with their oral health condition is influenced not only by 
clinical variables but also by intrinsic and personal factors that need to be further explored to identify and strengthen those that contribute to a positive perception of health. While there are still controversies, research has shown that SOC may change through life and is not as stable as originally proposed ${ }^{2}$. Therefore, SOC is capable of being stimulated by health promotion actions at different life phases.

\section{Collaborations}

RS Davoglio contributed to conception, design, data acquisition, analysis and interpretation, drafted and critically revised the manuscript. VN Fotanive contributed to design, data acquisition, drafted and critically revised the manuscript. MMC Oliveira contributed to design, analysis, drafted and critically revised the manuscript. C Abegg contributed to conception, design, analysis and interpretation, drafted and critically revised the manuscript. All authors gave final approval and agree to be accountable for all aspects of the work.

\section{Acknowledgements}

Research Support Foundation from State of Rio Grande do Sul (FAPERGS), National Counsel of Technological and Scientific Development $(\mathrm{CNPq})$, volunteers and group of research.

\section{Conclusion}

The findings of the present study demonstrate that the SOC is positively associated with oral health-related quality of life, supporting the hypothesis that individuals with a strong SOC present less impact from oral health on the quality of life compared with those with a weak SOC. Taken together, these results suggest that SOC is a psychosocial factor that can provide protection against that impact.

\section{References}

1. Eriksson M, Lindstrom B. A salutogenic interpretation of the Ottawa Charter. Health Promot Int 2008; 23(2):190-199.

2. Eriksson M, Lindström B. Antonovsky's sense of coherence scale and relation with health: a systematic review. J Epidemiol Community Health 2006; 60(5):376-381.

3. Antonovsky A. Unraveling the mystery of health - how people manage stress and stay well. London: JosseyBass; 1987.

4. Antonovsky A. The Structure and Properties of the Sense of Coherence Scale. Social Science \& Med 1993; 36(6):725-733.

5. Antonovsky A. The Sense of Coherence: An Historical and Future Perspective. J Med Sci 1996; 32(3-4):170-178.

6. Suominen S, Blomberc H, Helenius H, Koskenvuo $\mathrm{M}$. Sense of coherence and health: does the association depend on resistance resources? A study of 3115 adults in Finland. Psychol Health 1999; 14(5):937-948.

7. Nilsson B, Holmgren L, Westman G. Sense of coherence in different stages of health and disease in northern Sweden: Gender and psychosocial differences. Scand J Primary Health Care 2000; 18(1):14-20.

8. Forbes DA. Enhancing mastery and sense of coherence: important determinants of health in older adults. Geriatr Nurs 2001; 22(1):29-32.

9. Eriksson M, Lindström B. Antonovsky's Sense of Coherence Scale and It's relation with quality of life: A systematic review. J Epidemiol Community Health 2007; 61(11):938-944.

10. Freire MCM, Sheiham A, Hardy R. Mothers' sense of coherence and their adolescent children's oral health status and behaviours. Community Dent Health 2001; 19(1):24-31.

11. Savolainen J, Knuuttila M, Suominen-Taipale L, Martelin T, Nordblad A, Niskanen M, Uutela A. A strong sense of coherence promotes regular dental attendance in adults. Community Dent Health 2004; 21(4):271-276. 
12. Bernabé E, Watt RG, Sheiham A, Suominen-Taipale AL, Nordblad A, Savolainen J, Kivimäki M, Tsakos G. The influence of sense of coherence on the relationship between childhood socioeconomic status and adult oral health related behaviours. Community Dent Oral Epidemiol 2009; 37(4):357-365.

13. Ayo-Yusuf OA, Reddy P, Van Den Borne BW. Adolescents' sense of coherence and smoking as longitudinal predictors of self-reported gingivitis. J Clin Periodontol 2008; 35(11):93-37.

14. Savolainen J, Suominen-Taipale AL, Hausen H, Harju P, Uutela A, Martelin T, Knuuttila M. Sense of coherence as a determinant of the oral health-related quality of life: a national study in Finnish adults. Eur J Oral Sci 2005; 113(2):121-127.

15. Bernabé E, Watt RG, Sheiham A, Suominen-Taipale AL, Uutela A, Vehkalahti MM, Knuuttila M, Kivimäki M, Tsakos G. Sense of coherence and oral health in dentate adults: findings from the Finnish Health 2000 survey. J Clin Periodontol 2010; 37(11):981-987.

16. Savolainen JJ, Suominen-Taipale AL, Uutela AK, Martelin TP, Niskanen MC, Knuuttila ML. Sense of coherence as a determinants of toothbrushing frequency and level of oral hygiene. J Periodontol 2005; 76(6):1006-1012.

17. Sipilä K, Ylöstalo P, Könönen M, Uutela A, Knuuttila M. Association of sense of coherence and clinical signs of temporomandibular disorders. J Orofac Pain 2009; 23(2):147-152.

18. Lindström B, Eriksson M. Salutogenesis. J Epidemiol Community Health 2005; 59: 440-442.

19. Fontanive V, Abegg C, Tsakos G, Oliveira M. The association between clinical oral health and general quality of life: a population-based study of individuals aged 50-74 in Southern Brazil. Community Dent Oral Epidemio 2013; 41(2):154-162.

20. Pereira KC, Lacerda JT, Traebet J. The Oral Impact on Daily Performances and Self-Reported Quality of Life in Elderly People in Florianópolis, Brazil. Oral Health Prev Dent 2009; 7(2):163-172.

21. Gomes AS, Abegg C, Fachel JMG. Relationship between oral clinical conditions and daily performances. Braz Oral Res 2009; 23(1):76-81.

22. Brasil. Ministério da Saúde (MS). Secretaria de Políticas de Saúde. Departamento de Atenção Básica. Área Técnica de Saúde Bucal. Projeto SB2000: Condições de Saúde Bucal da População Brasileira no ano 2000: manual do examinador. Brasília: MS; 2001.

23. Bonanato K, Paiva SM, Pordeus IA, Ramos-Jorge ML, Barbabela D, Allison PJ. Relationship between mothers' sense of coherence and oral health status of preschool children. Caries Res 2009; 43(2):103-109.

24. Davoglio RS, Abegg C, Fontanive VN, Oliveira MMC, Aerts DRGC, Cavalheiro CH. Relationship between Sense of Coherence and oral health in adults and elderly Brazilians. Braz Oral Res 2016; 30(1):e56.

25. Suominen S, Helenius H, Blomberg H, Uutela A, Koskenvuo M. Sense of coherence as a predictor of subjective state of health: Results of 4 years of follow-up of adults. J Psychosom Res 2001; 50(2):77-86.

26. Adulyanon $S$, Sheiham A. Integrating perceived oral impacts into dental treatment need. International Association for dental research/South East Asia division, 12th annual meeting, Thailand; 1997.
27. Tsakos G, Marcenes W, Sheiham A. Evaluation of a modified version of the index of Oral Impacts On Daily Performances (OIDP) in elderly populations in two European countries. Gerodont 2001; 18(2):121130.

28. Abegg C, Fontanive VN, Tsakos G, Davoglio RS, Oliveira MMC. Adapting and testing the oral impacts on daily performances among adults and elderly in Brazil. Gerodont 2015; 32(1):46-52.

29. Kida IA, Åstrom AN, Strand GV, Masalu JR, Tsakos G. Psychometric properties and the prevalence, intensity and causes of oral impacts on daily performance (OIDP) in a population of older Tanzanians. Health Qual Life Out 2006; 4:56.

30. Instituto Brasileiro de Geografia e Estatística (IBGE). Perfil dos idosos responsáveis pelos domicílios no Brasil 2000. Rio de Janeiro: IBGE; 2002.

31. Freire MCM, Hardy R, Sheiham A. Adolescents' sense of coherence, oral health status, and oral health-related behaviours. Community Dent Oral Epidemiol 2002; 29(3):204-212.

32. Ayo-Yusuf OA, Reddy P, Van Den Borne BW. Longitudinal association of adolescents' sense of coherence with tooth-brushing using an integrated behaviour change model. Community Dent Oral Epidemiol 2009; 37(1):68-77.

33. Lindmark U, Hakeberg M, Hugoson A. Sense of coherence and its relationship with oral health-related behaviour and knowledge of and attitudes towards oral health. Community Dent Oral Epidemiol 2011; 39(6): 542-553.

34. Silva NA, Mendonca MHM, Vettore MV. A salutogenic approach to oral health promotion. Cad Saude Publica 2008; 24(Supl. 4):521-530.

35. Strauss RP, Hunt RJ. Understanding the value of teeth to older adults: influences on quality of life. JADA 1993; 124(1):105-110.

36. Fiske J, Davis DM, Frances C, Gelbier S. The emotional effects of tooth loss in edentulous people. Br Dent $J$ 1998; 184(2):90-93.

37. MacEntee I, Prosth D. Quality of Life as an Indicator of Oral Health in Older People. J Am Dent Assoc 2007; 138(Supl. 4):47-52.

38. Carr A, Gibson B, Robinson PG. Is quality of life determined by expectations or experience? $\mathrm{Br}$ Med $\mathrm{J}$ 2001; 322(7296):1240-1243.

39. Astrøm AN, Haugejorden O, Skaret E, Trovik TA, Klock KS. Oral Impacts on Daily Performance in Norwegian adults: the influence of age, number of missing teeth, and socio-demographic factors. Eur J Oral Sci 2006; 114(2):115-121.

40. Steele JG, Sanders AE, Slade GD, Allen PF, Lahti S, Nuttall N, Spencer AJ. How do age and tooth loss affect oral health impacts and quality of life? A study comparing two national samples. Community Dent Oral Epidemiol 2004; 32(2):107-114.

41. Hujoel PP. Endpoints in periodontal trials: the need for an evidence-based research approach. Periodontology 20002004 ; 36:196-204.

Article submitted 24/08/2017

Approved 02/08/2018

Final version submitted 04/08/2018 